\title{
Transformation: Examining the Implications of Emerging Technology for Journalism, Media and Society
}

\author{
By John V. Pavlik *
}

This paper examines the transformational implications of emerging technologies for journalism, media and society. An array of increasingly ubiquitous, global and networked technological developments is driving a sea-change in the nature and function of journalism, media and society. While low-cost, wide-spread digital technologies are empowering individuals to communicate and innovate, these same technologies are enabling governments, industry and others to engage in surveillance, censorship and control. This paper proposes that technological developments are reshaping media and society in four fundamental ways: 1) the participatory nature of journalism and media, 2) the methods of doing journalism and creating media, 3) the content and paracontent of journalism and media, and 4) the organizational structures, culture and institutional controls of journalism, media and society.

\section{Introduction}

In early 2014 news media reporting on political protests in Thailand used small, unmanned aerial vehicles (UAVs) called drones equipped with highdefinition video cameras to capture from the air moving pictures of the protests. Drone video is important in news reporting for several reasons, including providing a wider perspective on current events, non-government controlled access to news events, and less expensive aerial video than footage obtained via helicopter.

Such media use of drones to capture news video from the air is becoming increasingly common around the world (Associated Press 2014). But this is not the case in the United States. In the U.S., although there have been scattered uses of drones to capture video of news events, the U.S. Congress has been slow to enact legislation making commercial use of drones legal, including media use.

Drones are just one example of an array of increasingly ubiquitous, global, convergent and networked technological developments driving a sea-change in the nature and function of journalism, media and society (Pavlik and McIntosh 2014). While low-cost, wide-spread digital technologies are empowering individuals to communicate and innovate, these same technologies are enabling

*Professor, Rutgers University, USA. 
governments, industry and others to engage in surveillance, censorship and control. This paper proposes that technological developments are reshaping media and society in four fundamental ways: 1) the participatory nature of journalism and media, 2) the methods of doing journalism and creating media, 3 ) the content and paracontent of journalism and media, and 4) the organizational structures, culture and institutional controls of journalism, media and society.

We begin with an examination of ten emerging technological developments, each of which has profound implications for media and society, both good and bad. These technologies are representative of a broader set of digital, networked and convergent technologies, but they are not comprehensive in scope. The purpose here is to provide a framework for examining the consequences for media and society of emerging technologies, not a complete examination of all emerging digital technologies.

\section{Mobile Media}

In considering these emerging technologies, a logical starting place is the realm of mobile digital devices. Mobile communications have been in development since the early $20^{\text {th }}$ century (Wikipedia 2014; Katz 2008). Early car-based mobile communication systems have been in operation since the 1950s, including one automated-system tested in Sweden in 1955. In 1973, Martin Cooper demonstrated the first hand-held subscriber mobile phone system (Fluhr and Nussbaum 1973). But, these systems were all analog. Computerized, or digital, mobile communication devices were introduced in the 1990s and have rapidly accelerated in use since the early 2000s. Driving much of the rising global use of mobile digital communication devices has been the fact these smartphones represent convergent technologies capable of a wide range of functions, including not only communication, but Internet access, photography and videography, music playback, e-book capability, and geo-location tracking.

Notably, smartphones offer capabilities that enable their use in both consuming (including accessing online and displaying or playing back on demand) media content as well as producing and distributing it.

Mobile digital devices come in a variety of forms, functions and features, not to mention from various providers and network capabilities. Hand-helds include smartphones as well as tablets and e-reader devices, such as Amazon's Kindle (Amazon 2014). While public adoption of these devices has generally been rapid in the U.S. and much of the world since the early 2000s, the fastest growth in use since 2011 has been among the young, especially the very young. A study released in late 2013 shows that over the previous two years, use of mobile, digital devices among those two or younger has tripled, from 12 percent to 38 percent, in the U.S. (Wagner 2013). By age 8, 72 percent of children in the U.S. have access to a smartphone or tablet. 
The principle players in terms of the production and distribution of mobile digital devices are Apple (iPhone smartphone, iPad tablets; Apple 2014), Samsung (Galaxy smartphones and tablets) and Amazon (Kindle e-readers), with Google playing a key role in software (Android) development and the looming wearable environment, discussed later in this paper. Mobile devices are still in a state of rapid transition and innovation, making their use an evolving story for media applications. Mobile devices are already widely used for many media consumer behaviors, including news (mostly on a variety of apps, including social media such as Twitter), music, e-reading and video consumption. Media production also is heavily engaged in mobile media, as well, including both professional use for audio, video and other content creation and distribution, but also citizen media production, as in citizen journalists or reporters and social media in the form of text, audio and video.

Recently introduced are new capabilities, including biometrics, such as thumbprint scanning, with implications for security (discussed later in this paper) and more. The interface for mobile media is evolving rapidly in this sense, as well. The Samsung Galaxy 4s has gesture control, enabling users a more intuitive means of controlling their device (Samsung 2014). Flexible displays such as the curved smartphones from LG and Samsung are entering the marketplace, promising not only a more natural user experience but also new capabilities for displaying content (LG 2014). E-readers such as the Amazon Kindle Paperwhite offer light-weight, touch screen, glare free, high contrast, front-lit, e-ink technology, Wi-Fi, and batter life with up to 8 weeks of reading time for a relatively low price (about \$119). Tablets such as Apple's iPad or Samsung's Galaxy Tab offer similar capabilities, although at slightly higher prices and certain additional functionalities and design features. Consumers are rapidly adapting to the use of these devices to consume media content, especially e-books, but other uses as well, such as email, social media, and music playback. Many consumers also install e-reader software on their smartphones, and use those devices for e-book reading. Consequently, e-book reading is accelerating rapidly in the U.S. and worldwide. The Pew Research Center (2014) presents evidence that e-books are particularly popular among the young. As a January 2014, nearly half (47 percent) of U.S. adults ages 1829 have read an e-book in the past year. This is double the figure from 2011. Slightly less (42 percent) of U.S. adults 30-49 have read an e-book in the past year, as of Jan. 2014 (up about 66 percent since 2011). Those 50-65 and 66 and older are also increasingly reading e-books, although at slightly lower levels. While overall book reading is stable, Pew reports, e-book reading is likely to be the dominant platform within one to two years.

E-books offer a variety of advantages to both readers and publishers, as well as to authors. E-books also have certain disadvantages. Among the advantages to consumers are the ability to have access through their Internet connectivity to literally millions of books on demand, many of which are classics in the public domain and free. Moreover, many e-books are available at a lower price than their printed counterparts, although there have been legal challenges by U.S. government authorities against Apple and other e-book 
publishers for price collusion designed to hold the price of e-books artificially high. E-books also offer the consumer the ability to keyword search, create searchable digital annotations, engage in social reading, and more. Moreover, e-reader devices enable the consumer to carry with her or him hundreds or more e-books, far more than could be carried in even the largest backpack filled with analog printed books.

For publishers, e-books offer a host of advantages, including near-zero printing marginal cost structures, and more including streamlined distribution systems via the Internet. Authors also enjoy the capability of including interactive and multimedia content to enhance their traditional long-form textformatted narratives.

Disadvantages also come with e-books. Among the most important is the limited ability for the consumer to share their e-books. Further, publishers (and government) have the ability to track or monitor e-book distribution and readership. In one case, Amazon even surreptitiously deleted copies of an ebook (ironically, George Orwell's dystopian novel 1984) when it discovered it lacked the appropriate copyright permissions to distribute the e-book in the U.S. Consumers and privacy rights groups roundly criticized Amazon for the ill-conceived action, and filed lawsuits against the e-retail behemoth. Amazon ultimately apologized and promised not to commit such an invasive action again... but the Pandora's box has been opened.

\section{Mobile Broadband Networking}

Complementary to and enabling mobile device use is mobile broadband networking capacity. Mobile broadband networking capacity is vital to mobile device use because it permits users, whether consumers or producers of media, to communicate and access the Internet. Broadband is important because mobile users are increasingly engaging high-bandwidth media content, including audio and video, as well as emerging forms such as augmented and virtual reality (discussed later in this paper) and online gaming. In 2014, the two main forms of broadband networking are Wi-Fi and cellular. Wi-Fi offers mobile users the advantages of generally free, high-speed or high-capacity Internet access, although mobility is limited to the range of the Wi-Fi hot spot. Wi-Fi hot spots are generally secure, requiring log-in and password. Cellular networks are increasingly high capacity, as telecommunications providers role out 3G, 4G and next-generation wireless network capacity supporting smartphones, tablets and wearables. The increasingly ubiquitous nature of broadband networking supports not only consumer use of broadband mobile applications but also professional media usage. One of the transformative capabilities for media as broadband networking converges with low-cost storage and server capacity is cloud computing. Cloud computing, such as Google Drive, means content can be kept on the cloud rather than only on the individual device (Google 2014). This supports the development of the virtual newsroom or other media organization. At the same time, it means content 
resides on a server not under the control of the user, creating potential privacy concerns.

High-speed networking presents at least two other social problems. One is called network neutrality (Lessig and McChesney 2013; Krämer, Wiewiorra, and Weinhardt 2013). This refers to the notion of giving all users or providers the same access at the same cost to the network, regardless of the nature of their usage. It means traditional network providers are not advantaged in the network. Unfortunately, recent regulatory decisions in the U.S. have favored the incumbent network providers. This bodes against future open and equal mobile network usage and will likely inhibit innovation in the mobile media arena.

The second major issue is known as the digital divide. Historically, those less economically advantaged have had more limited access to digital technologies, because of their expense. This problem has been apparent not just domestically in the U.S. (e.g., Native American reservations and some inner city and rural communities) but in much of the developing world, such as subSaharan Africa. Overall mobile Internet usage varies widely around the world (Pew 2013). As of 2013, in the U.S., for instance, 85 percent of the population uses mobile Internet access. In contrast, in Russia and Chile, for instance, just two-thirds (66 percent) use the Internet, whether from computer or mobile device. About half (55 percent) of the population in China use fixed-line or mobile Internet. Meanwhile, less than half (43 percent) of those in South Africa use Internet (fixed or mobile) and just a quarter (26 percent) of those in Ghana use the Internet (fixed or mobile).

In this sense, it is vital to consider the economic, social and political impact of emerging media technologies, both good and bad (Pool and Schiller, 1981; Chakravartty and Sarikakis 2006). Some scholars have outlined the negative impact of the Internet and related developments on journalism (McChesney and Pickard 2011). Others have pointed to the potential positive economic, social and cultural influence networked technologies may exert (Castells 1996). Morozov (2013) has cautioned against relying on technological solutions to a wide spectrum of social, political or economic problems.

Some commercial players have introduced new, innovative approaches to remedy the digital divide problem in the mobile networking arena. Facebook and Google both have strategies. Google's Loon for All is an approach to deliver free mobile Wi-Fi Internet access to many in Africa and elsewhere via high-altitude balloons delivering free broadband bandwidth at very low cost to Google. Providing ubiquitous network access offers not only goodwill to the providers. In the context of Metcalfe's law, which suggests the value of the network increases in proportion to the overall rate of connectivity or access to the network, increasing network access offers long-term economic incentives to both the network providers and commercial users such as media (Tongia and Wilson 2007). What the consequences are for the end user, or public, is unclear and represents an important topic for research as well as policy considerations. 


\section{Wearable Computers, Including Immersive Media}

Building on the foundation already established by mobile and broadband wireless media are developments in the arena of wearable digital devices. Wearable digital media and communications devices have been in development for some four decades. Based on Vannevar Bush's description of a wearable camera in his seminal "As We May Think" article in a 1945 issue of the Atlantic Monthly, Steve Mann developed a wearable computer with camera and communications capability and tested it in 1978 (Bush 1945; Mann and Niedzviecki 2001). Others have built on this work and in 2013 Google introduced a program called Google Explorer to test its prototype wearable computer and display called Google Glass (Google 2014). The author is a participant in the Google Explorer program and has been testing the system's media applications. As Glass enters the consumer arena in the coming months, it is likely to find opportunities for innovation in the media arena. Journalists, whether professional or citizen, will find ways to create first-person documentaries, as Glass "sees" what-ever the wearer sees, and can record and transmit photos or live audio and video. Social media applications are also likely, as are capabilities for augmented reality.

Augmented reality (AR) refers to the overlaying of media content onto user views or other real-world experiences. For instance, imagine a person wearing Glass or another head-worn digital display standing in front of a historic site. She or he would see the site as it appears today. But, using augmented reality, she or he could see digital imagery, graphics, photos or video from an archive of past views of that site, overlaid onto the contemporary scene. Stitched together with narrative, such AR experiences could tell firstperson stories of the past. Feiner, Pavlik and Höllerer (1999) and their students have created prototypes of such AR narratives, calling them Situated Documentaries, as the user experiences virtually past events in the location, or situation, where they previously occurred.

Wearable devices with cameras bring a duality of privacy considerations. On the one hand, as they can provide the user a discreet means to photograph or video record people and places, wearables pose a threat to individual privacy. Yet, conversely, wearables can enable user privacy protections, by permitting ready capture of events and places for users to document their own real-world experiences. Against a backdrop of communities, companies and countries installing nearly ubiquitous and networked cameras to capture video of individuals and events in their field of view, Mann and others have demonstrated how wearable cameras can provide citizens with a means to protect their own civil liberties.

Google is not the only commercial enterprise to develop wearable devices. SpaceGlasses from Meta (Meta 2014) and the Vuzix M100 (Vuzix 2014) are already in 2014 available in the commercial marketplace. The Samsung Galaxy Gear smart watch became available to consumers in 2013 (Samsung 2013). On the horizon are retinal displays capable of AR applications. 
Virtual Reality (VR), or computer-synthesized environments, has been rapidly moving from the realm of research to the mainstream consumer marketplace. An early and promising entrant into this arena is the Oculus Rift Virtual Reality (VR) display (Oculus 2014). Designed for VR games, Oculus Rift offers consumers a powerful immersive form of media. Facebook in 2014 bought Oculus VR for $\$ 2$ billion, underscoring the commercial potential of VR.

Related here as well are consumer game consoles such as the Nintendo Wii, which employs kinesthetic technology (Wikibooks 2014). These devices enable a more intuitive, natural and immersive user experience, without requiring typing to control the computer or enter information. Google Glass utilizes speech recognition as an efficient, and reliable, form of user control, as well. The author has tested the speech recognition on Glass and found it to be nearly 100 percent reliable. The primary limitations seem to be the speech recognition only works when networked enabled, which suggests certain privacy and security concerns, and dictation requirements, if the user wants to insert punctuation.

\section{Tactile, Haptic Interfaces}

Extending the potential suggested in wearable technology are hapticenabled or haptic devices and displays. Tactile displays enable users to virtually feel digital objects. Disney has developed a prototype system that uses miniature air canons embedded into tablets and other systems that use micro electronic vibrations to simulate textures and other surfaces, permitting users to "feel" the things they see, such as the surface of a virtual ball (Vanhemert 2013). Such haptic interfaces are not only highly intuitive for users, but present profound opportunities for media content innovation, such as permitting storytellers to use touch. One demonstration system allows users to "feel" objects floating virtually in the air (McNicoll 2013).

\section{D Media}

Already in the consumer marketplace, but only beginning to capture the widespread attention of media storytellers, are a wide range of threedimensional (3D) media. A number of movie-makers have experimented, increasingly successfully, with 3D media. Moving beyond the realm of 3D gimmickry, directors such as Peter Jackson (The Hobbit), James Cameron (Avatar) and Ang Lee (Life of Pi) have employed 3D to tell stories. 3D movie viewing still generally requires the user to wear a special set of stereoscopic glasses, but technological advances are rapidly moving toward a nextgeneration interface that will not require the user to done the 3D glasses. Such technology is also entering the home and wearable marketplace, to enable wide-spread consumer 3D media. 3D video games are emerging as an early 
success in the commercial marketplace, with 3D products such as Halo and Nintendo 3DS games. 3D graphics and other user interfaces have been slower to develop in the journalism realm, but are in development. 3D geographic information system (GIS) modeling is among the earliest examples of news uses of 3D modeling to tell stories or present news information. These enable not only data-driven presentations (more on this later in the paper), but also interactive graphics that permit user exploration and customization. Nextgeneration large display smart TVs and 4K OLED (organic light-emitting diode) displays present new super-high resolution 3D imagery (Samsung 2014). The light-emitting diode (LED) display contrasts with more convention Liquid Crystal Display (LCD) technology available today. LED displays also function with less power requirements and stay cooler.

For media producers, 3D video requires the use of stereoscopic cameras. Once very expensive and generally immobile, such stereoscopic cameras are increasingly inexpensive, light-weight, mobile and high resolution, enabling relatively easy 3D video capture. Linked with geo-tagging of video, the potential for immersive, location-based 3D video is rapidly approaching (Pavlik and Vance 2013). Wearable stereoscopic camera technology is also emerging, mirroring human vision.

$3 \mathrm{D}$ printing is also rapidly moving out of the realm of high-end, expensive manufacturing into the consumer marketplace. Brooklyn, NY-based MakerBot has announced (MakerBot 2014) a consumer-friendly \$1400 3D printer and 3D digitizer (i.e., for rendering physical objects into 3D computer format). Together, media professionals and amateurs will be able to create 3D objects to enrich their other storytelling palette. Imagine NASA's Mars Rover encountering a fossil, demonstrating life once existed beyond the Earth. The Rover could capture the 3D image of the fossil via laser or stereoscopic camera scan, and transmit the 3D image or video back to Earth. Storytellers could use words, audio and video from Mars and NASA scientists and archeologists and other relevant experts to tell the story, and anyone with a 3D printer at home, in school or a library could download a 3D facsimile of the fossil, print it out in a few minutes, and hold a physical replica of that fossil.

\section{Artificial Intelligence (AI) \& Algorithms}

Already introducing dramatic changes in journalism and media are the fields of data and computer science. What some call computational journalism or computational media, data-driven reporting is already becoming mainstream. With roots in the pioneering precision journalism of Philip Meyer (1967) nearly five decades ago, reporters around the world now use algorithms to process and help analyze public records on a wide swath of stories. These tools enable reporters to sort through so-called "big data" to find patterns or outliers in investigations of government, big business or others. Whistle-blower Edward Snowden and Guardian journalist Glenn Greenwald (2013) put a dramatic spin on big data when they put the world on alert to the top-secret 
digital surveillance program called PRISM operated by the U.S. government National Security Agency (NSA).

Applying a branch of artificial intelligence known as natural language processing to big data, a number of pioneering computer, data and journalism scientists have developed powerful data-driven machine writing applications (Siddharthan, Nenkova and McKeown, 2011). Northwestern University's Lawrence Birnbaum has lead a team that developed a tool called Narrative Science, which is capable of writing news stories from data (Birnbaum 2012). Among the enterprise's first paying clients are companies in sports, finance and health care. Media clients include Forbes. Stories written by Narrative Science already number in the millions, and are generally well-written, indistinguishable from human-written stories, and therefore pass the famous Turing Test (i.e., can one tell whether a communication is from a computer or human; Turing 1950). Here's a lead from Forbes.com published on 12 February 2014. Was it written by human or machine? "Analysts expect higher profit for Scripps Network Interactive when the company reports its fourth quarter results on Friday, February 14, 2014. The consensus estimate is calling for profit of 97 cents a share, reflecting a rise from 84 cents per share a year ago." As of 14 February it was viewed by $32 \ldots$ byline: Narrative Science (Narrative Science 2014).

Does machine writing threaten the jobs of journalists? Perhaps. The decline in revenues to traditional news media is an even greater threat. Moreover, another perspective on machine writing is that it is a compelling reason for human journalists to take their game to the next level. Human journalists need to focus on the stories only humans can do. This means investigative work that relies on a combination of good old shoe-leather reporting and data-driven analysis. It means moving beyond the superficial and to drill in deep for the stories that lie beneath the surface. It means writing in a style that is not formulaic and more like Ernest Hemmingway: clear, compelling, and concise (Kaneshige 2014). Of course, there is now an app to help an author write like Hemmingway, but that's another article.

\section{Drones}

Unmanned miniature aerial vehicles (UAVs), called drones, are becoming a commercial mainstay around the world. Known widely as military technology, drones have increasingly common commercial uses, including in the United Arab Emirates (UAE), where a new venture has been announced to introduce drones for making home deliveries (Lynch 2014). Amazon's founder Jeff Bezos, who recently bought the Washington Post newspaper, has announced similar plans to use drones to deliver small products in fewer than 30 minutes (Barr 2013). The only real obstacle to his plans is the U.S. government's slow actions to clear legal hurdles preventing commercial uses of drones in the U.S. 
Meanwhile, media organizations around the world have already been using drones for a variety of news reporting and documentary production. Drones are much cheaper than other standard aerial video technologies such as helicopters. Moreover, they are much safer and easier to pilot. The author recently purchased his own drone equipped with a high definition video camera, capable of geo-tracking, and piloted remotely via smartphone or tablet. Such drone video can be transmitted or shared in real time or via social media such as YouTube (Parrot 2014).

When integrated with artificial intelligence-driven algorithms, drones are capable of remarkable athletic maneuvering. Raffaelo D'Andrea has developed an advanced drone robotics lab at TEDGlobal, where teams of quadcopters can actively collaborate in real time and autonomously play catch with a human tossing a ball into the air (TED 2013).

Despite their compelling and low-cost capacity to produce unique video, drones should not be used as a substitute for human, journalist-on-the-ground reporting. Journalists on location can make observations, ask questions and conduct interviews that might yield critical information not always available from a remotely piloted drone.

\section{Geo-Located Technology}

Geo-located media is emerging as an important application for both drones and other video cameras. Commercial applications such as those from Kinomap make creating geo-located video a simple and inexpensive process for smartphone or tablet. Pavlik and Vance (2013) conducted a demonstration project to illustrate both the ease of creating and distributing geo-located video as well as accessing it via the Web, using keyword search or channels. Drones with HD video and other sensors using geo-location are also rapidly entering media mainstream.

Geo-location in video is important for at least three reasons in a media context. First, the geo-location of news video, including that collected by citizen reporters, can help establish the veracity of the content, by providing an independent measure of the location, date and time of the acquisition of the video. This can help in documenting the authenticity of video captured in conflict zones and elsewhere.

Second, geo-located video can be used to help provide a strong digital watermark to protect the intellectual property rights of reporters, including those working in free-lance fashion.

Finally, geo-location has intriguing possibilities for storytelling innovations. For instance, geo-tagged video can be used in games and also in augmented reality to situate that video in specific locations and orientations for individual users using hand-held or wearable devices. 


\section{Security}

Geo-location also presents profound security as well as privacy implications. Devices that users carry with them that also provide precise locational information have dramatic and intriguing potential for media innovation. Four Square and other social media provide news and other location services for users. But they also provide a vehicle for law enforcement to track the individual. While such tracking may be valuable in fighting crime or terrorism, it also brings enormous threats to civil liberties. This was brought to dramatic light in 2013 when whistleblower Edward Snowden and Guardian journalist Glenn Greenwald revealed the top secret surveillance program called PRISM operated by the U.S. government's far-reaching National Security Agency (NSA). While much of what has been revealed as of this writing involved surveillance of digital communications including voice and email, the capability for location-based tracking is evident. It means governmental agencies and other enterprises have the potential to track users where-ever they go.

Cyber-security is also a significant concern for media organizations. Whether in the form of hacking news and other media web sites and applications, or engaging in other forms of illegal activity such as identity theft, cyber-security has become a real, substantial, expensive and global issue for today's media organizations. Most have been inadequately prepared to deal with cyber-security, especially in an age of cloud computing, as the Syrian Electronic Army's repeated cyber-attacks on major media organizations such as The New York Times, Washington Post, and the Associated Press illustrate (Noman 2013).

\section{Crowdfunding: Entrepreneurship and an Evolving Business Model}

Digital developments have exerted profound and far-reaching influences on traditional media, including news organizations that have struggled oftentimes to adapt to an online, digital marketplace. In the U.S., this has often manifested itself in the form of dramatic layoffs of employees at media organizations, closures of many newspapers and digital ventures that have only slowly built funding models that can support original, quality content creation and distribution in a digital, networked and mobile environment. News has often become a commodity and users have shown only a grudging willingness to pay for content that they are accustomed to receiving for free or at low cost often subsidized by advertising. In the digital space, advertisers have increasingly discovered far more efficient vehicles for reaching potential consumers than the traditional mass media. While some traditional media have managed to gradually convert their business model to the digital age, most have at been seen their analog dollars convert to digital pennies.

One interesting opportunity in funding for digital media comes in the form of the controversial new crypto currency called Bitcoin (Steadman 2013). 
Launched as an open-source, peer-to-peer platform in 2009, Bitcoin garnered not only the interest of venture capitalists such as Internet entrepreneur Marc Andreesen, but also the scrutiny of security experts and law enforcement. Bitcoin uses an entirely digital system of payments based on transactions to and from digital wallets such as Blockchain. Bitcoin was the currency used for the sale of illegal drugs on the secretive network called the Silk Road (Blockchain 2014). It is based on peer-to-peer exchange, and has seen its value against the U.S. dollar rise and fall dramatically. As of this writing (8 March 2014 ), a single Bitcoin was valued at about $\$ 627$, about half its highest value of six months earlier. For media entrepreneurs entering into the Bitcoin realm opens new possibilities to engage a high-tech audience (e.g., by permitting audience members to pay for media content with Bitcoins) likely also drawn to emerging technology...but also risks.

Another relatively new opportunity for entrepreneurial digital media ventures comes in the form of crowdfunding. Online crowdfunding sources such as Kickstarter and Indiegogo have already given innovators with a compelling idea the opportunity to support at least the development of a new initiative (Kickstarter 2014; Indiegogo 2014). Illustrative are a series of music video crowdsourced ventures, documentaries funded through crowdsourcing, and new media technology endeavors. The Oculus Rift VR project is among the most impressive examples of crowdfunding. Palmer Luckey, inventor of the virtual reality goggles called Oculus Rift, was a student of journalism at Cal State Long Beach (Martens 2013). Departing journalism school, he raised some $\$ 2$ million on Kickstarter to create a VR system for the consumer market. As of March 2014, Kickstarter had raised an impressive US \$1 billion in support for creative projects. Contributions have come from 5.7 million persons in 224 countries and territories on all seven continents.

\section{Conclusions: Four Sets of Consequences}

Digital developments outlined in this paper present profound implications for media and society. These implications fall into four broad areas of media transformation. First is how media professionals (or amateurs) do their work, especially in the process of creating content (e.g., the digital transformation of news gathering with a world-wide and nearly ubiquitous mobile citizen reporter work-force).

Second is the transformation of storytelling. Interactivity, immersiveness and three-dimensionality are among the ways storytelling is changing, both in news and entertainment media. Video games and other media forms are increasingly finding online, community-based usage. Geo-location and other new capabilities are set to drive further transformations in media content.

Third are organizational, cultural and managerial transformations. Among the first seen in this regard are shifts in funding for media organizations as well as new management structures that engage cloud computing.

Fourth are shifts in the relationship between media and the public. This vital relationship is undergoing a fundamental transformation, particularly with 
the rise of mobile and social media. Public engagement is increasingly the defining characteristic in the media-public relationship. Members of the public are more and more serving as producers of content, whether in the form of text, photos or video. Twitter, for instance, has emerged as a global, real-time news source, with many Tweets and re-Tweets coming from the public. Many now think that if news is important, it will find them, mostly through social media. For better or worse, real-time Tweets have become powerful sources of news or at least news-like data. Athletes at the 2014 Olympic Games in Sochi, Russia, saw their followings grow from a few hundred to tens or even hundreds of thousands by posting Tweets during the games (Twitter 2014). Notably, most of these capabilities are driven by commercial technology and technology companies that may or may not share a commitment to social responsibility, freedom of speech and civil liberty that characterized many of the traditional news media throughout the $20^{\text {th }}$ century. These legal, regulatory and constitutional concerns transcend international boundaries as well, pitting the people's right to know (i.e., First Amendment) against the people's right to privacy (i.e., Fourth Amendment).

Moreover, none of these developments implies a technological deterministic framework. Transformation of media is far more than simply a response to technological developments. Instead, developments in technology are more appropriately understood as enabling changes in media and the public, whether for good or bad. The transformative pathway is shaped by a variety of competing forces, including individual entrepreneurship, commercial interests, and regulatory and legal frameworks, all situated in a web of social and cultural contexts around the globe. Further research is urgently needed to examine how these developments are taking shape and what directions they may take and influences they may exert in an emerging post-disconnected world.

\section{Post-Script: The Paradox of Schrödinger's Cat}

Consider a famous thought experiment in quantum physics. In this experiment, a cat is placed in box and exposed to a potentially lethal dose of radiation (Wikipedia 2014). Posited by Austrian physicist Erwin Schrödinger in 1935, the cat is simultaneously both alive and dead, existing in both forms in parallel universes. Apply the paradox of Schrödinger's cat to the impact of digital technologies on journalism, media and society. Can the effects of these technologies be simultaneously destructive (e.g., eroding privacy, expanding surveillance) and beneficial (e.g., enabling, fostering democracy, freedom of speech, transparency)?

\section{References}

Amazon. http://www.amazon.com/Kindle-Paperwhite-Ereader/dp/B00AWH595M Retrieved 14 February 2014. 
Apple. https://www.apple.com/iphone-5s/; https://www.apple.com/ipad/ Retrieved 14 February 2014.

Associated Press. "Drone use highlights questions for journalists." USA Today. http:// www.usatoday.com/story/tech/2014/02/11/us-drones-faa-media/5390155/ Retrieved 14 February 2014.

Barr, Alistair (2 December 2013). "Amazon testing delivery by drone, CEO Bezos says." http://www.usatoday.com/story/tech/2013/12/01/amazon-bezos-drone-deli very/3799021/ Retrieved 11 March 2014.

Birnbaum, Larry. Transforming Data into Stories and Insight: Scaling Human Editorial Judgment." February 15, 2012. https://groups.google.com/ forum/\#!msg /chicago-chapter-acm/e5NNk93ddA0/c_ElrP6KYPUJ

Blockchain (2014). http://blockchain.info/wallet Retrieved 8 March 2014.

Bush, Vannevar. "As We May Think" 1 July 1945. Atlantic Monthly. http://www.the atlantic.com/magazine/archive/1945/07/as-we-may-think/303881/ Retrieved 14 February 2014.

Castells, Manuel (1996, second edition, 2000). The Rise of the Network Society, The Information Age: Economy, Society and Culture Vol. I. Cambridge, MA; Oxford, UK: Blackwell. ISBN 978-0-631-22140-1.

Chakravartty, Paula and Katharine Sarikakis. Globalization, Communication and Media Policy: A Critical Perspective. Edinburgh University Press, 2006 \& Palgrave North America.

Fluhr, Z. and E. Nussbaum. "Switching Plan for a Cellular Mobile Telephone System" IEEE Transactions on Communications volume 21, \#11 p. 1281 (1973).

Google. http://www.google.com/glass/start/ Retrieved 14 February 2014.

Google. https://drive.google.com/ Retrieved 14 February 2014.

Greenwald, Glenn. http://www.theguardian.com/world/the-nsa-files 4 October 2013. Retrieved 14 February 2014.

Höllerer, T., S. Feiner, J. Pavlik, "Situated Documentaries: Embedding Multimedia Presentations in the Real World," In: Proc. ISWC '99 (Third Int. Symp. On Wearable Computers), San Francisco, CA, October 18-19, 1999, pp. 79-86.

Indiegogo (2014). http://www.indiegogo.com/ Retrieved 14 February 2014.

Information Status Distinctions and Referring Expressions: An Empirical Study of References to People in News Summaries. Journal of Computational Linguistics accepted with revisions, 2011.

Kaneshige, Tom. 14 February 2014. "The Art of Writing in the Age of Algorithms." CIO.com. http://www.cio.com/article/748267/The_Art_of_Writing_in _the_Age_ of_Algorithms?page=2\&taxonomyId=3000 Retrieved 16 February 2014.

Katz, James E. (2008). Handbook of Mobile Communication Studies. Boson, MA: Massachusetts Institute of Technology.

Kickstarter (2014). https://www.kickstarter.com/ Retrieved 14 February 2014.

Krämer, J, Wiewiorra, L. \& Weinhardt, C. (2013): "Net Neutrality: A progress report". Telecommunications Policy 37(9), 794-813.

Lessig, Lawrence and Robert W. McChesney (8 June 2006). "No Tolls on The Internet". Columns. http://www.im.uni-karlsruhe.de/Upload/Publications/336c3 9b3-7a62-4159-bb1a-483f39dd5b24.pdf Retrieved 14 February 2014.

LG. http://www.lg.com/us/mobile-phones/gflex Retrieved 14 February 2014.

Lynch, Tyler Wells. UAE to launch eye-scanning delivery drones. USAToday. Retrieved 14 February 2014. http://www.usatoday.com/story/tech/2014/02/ 11/dubai-delivers-ids-via-drone/5391001/

MakerBot. http://www.makerbot.com/ Retrieved 14 February 2014. 
Mann, Steve and Hal Niedzviecki (2001). Cyborg: Digital Destiny and Human Possibility in the Age of the Wearable Computer. Randomhouse Doubleday. ISBN 9780385658263.

Mann, Steve. http://wearcam.org/netcam_privacy_issues.html_Retrieved 14 February 2014.

Martens, Todd. 08 June 2013. Latimes.com http://herocomplex.latimes.com/games/ palmer-luckeys-oculus-rift-could-be-a-virtual-reality-breakthrough/ Retrieved 14 February 2014.

McChesney, Robert W. and Victor Pickard, editors (2011). Will the Last Reporter Please Turn out the Lights: The Collapse of Journalism and What Can Be Done to Fix It. New York: The New Press.

McNicoll, Arion. "“Feel' objects in thin air: The future of touch technology." CNN 29 October 2013. http://www.cnn.com/2013/10/29/tech/innovation/feel-objectsin-thin-air/index.html Retrieved 14 February 2014.

Meta. https://www.spaceglasses.com/ Retrieved 14 February 2014.

Morozov, Evgeny (2013). To Save Everything, Click Here: The Folly of Technological Solutionism. New York: PublicAffairs.

Narrative Science. http://www.forbes.com/sites/narrativescience/_12 February 2014. Retrieved 14 February 2014.

Noman, Helmi. "The Emergence of Open and Organized Pro-Government Cyber Attacks in the Middle East: The Case of the Syrian Electronic Army". Open Net Initiative. Retrieved 22 July 2013.

Oculus Rift. http://www.oculusvr.com/ Retrieved 14 February 2014.

Parrot (2014). http://www.youtube.com/user/ARdrone Retrieved 10 March 2014.

Pavlik, John and Shawn McIntosh. https://www.facebook.com/convergingmedia Retrieved 14 February 2014.

Pavlik, John V. and Robert Vance. "Geolocated Video in Qatar: A Media Demonstration Research Project." Presented at the Qatar Foundation Research \& Development Annual Research Conference November 24-25, 2013, Doha.

Pew Research Center. http://www.pewresearch.org/fact-tank/2014/01/21/overallbook-readership-stable-but-e-books-becoming-more-popular/ Retrieved 14 February 2014.

Pool, Ithiel de Sola and Herbert I. Schiller. "Perspectives on Communications Research: An Exchange." Journal of Communication Volume 31, Issue 3, pages 15-23, September 1981.

Samsung. http://www.samsung.com/global/microsite/oledtv/ Retrieved 14 February 2014.

Samsung. http://www.samsung.com/us/guide-to-galaxy-smart-devices/galaxy-s-4-sma rtphone.html Retrieved 14 February 2014.

Samsung. http://www.samsung.com/global/microsite/galaxynote3-gear/ Retrieved 14 February 2014.

Siddharthan, A., Nenkova, A., and McKeown, K.

Steadman, Ian (2013-05-11). "Wary of Bitcoin? A guide to some other cryptocurrenci es". Ars Technica. Retrieved 2014-01-10.

TED. "Raffaello D'Andrea: The astounding athletic power of quadcopters." http:// www.ted.com/talks/raffaello_d_andrea_the_astounding_athletic_power_of_quad copters.html Retrieved 14 February 2014.

Tongia, Rahul and Ernest Wilson (September 2007). "The Flip Side of Metcalfe's Law: Multiple and Growing Costs of Network Exclusion". Retrieved 2013-01-15.

Turing, Alan (October 1950), "Computing Machinery and Intelligence", Mind LIX (236): 433-460, doi:10.1093/mind/LIX.236.433. 
Twitter. http://www.tweeting-athletes.com/index.cfm?CatID=406\&People=1 Retrieved 14 February 2014.

Twitter. https://twitter.com/FactTank/status/434010023891464192/photo/1 Retrieved 14 February 2014.

Vanhemert, Kyle. "Watch: Disney's Experimental Touchscreens Let You 'Feel' Digital Objects." Wired. http://www.wired.com/design/2013/10/disneys-magictouchscreens-let-you-feel-apps-with-your-fingertips/ 21 October 2013. Retrieved 14 February 2014.

Vuzix. http://www.vuzix.com/augmented-reality/products_m100ag/ Retrieved 14 February 2014.

Wagner, Meg. 28 October 2013. "38\% of Children Under 2 Use Mobile Media, Study Says.” http://mashable.com/2013/10/28/children-under-2-mobile-media-study/ Retrieved 14 February 2014.

Wikibooks. http://en.wikibooks.org/wiki/Web_2.0_and_Emerging_Learning_Techno logies/Learning_Styles Retrieved 14 February 2014.

Wikipedia. http://en.wikipedia.org/wiki/History_of_mobile_phones\#cite_ref-See_Am os_Joel_patent_3.2C663.2C762_18-0 Retrieved 14 February 2014.

Wikipedia. "Erwin Schrödinger." http://en.wikipedia.org/wiki/Erwin_Schr\%C3\%B6 dinger Retrieved 14 February 2014. 